\title{
Loads on barricades in hydraulically backfilled underground mine stopes
}

\author{
SD Widisinghe James Cook University, Australia \\ N Sivakugan James Cook University, Australia \\ VZ Wang James Cook University, Australia
}

\begin{abstract}
In the recent past, there has been significant growth in underground mining due to the ever increasing demand for resources and the advancement in technologies. The post-processed tailings are directed back into the mine stopes as backfill, with barricades in place to retain the backfills. Failure of the barricades can be catastrophic and several accidents have been reported in Australia and worldwide that have resulted in fatalities. Proper understanding of the loading on the barricades is necessary to design them with confidence, thus ensuring safe mining practices.

The object of this paper is to discuss some laboratory model tests carried out at James Cook University laboratory to investigate the stresses within drives. A novel laboratory apparatus was developed where a cylindrical container with a horizontal drive, filled with dry hydraulic fill, was loaded by the MTS machine. The vertical stresses at the bottom of the stope, near the wall, and the horizontal stresses on the drive were measured using earth pressure cells. This was also simulated numerically using a finite difference code Fast Lagrangian Analysis of Continua for three dimensions (FLAC3D). Results are compared from three approaches and implications are discussed.
\end{abstract}

\section{$1 \quad$ Introduction}

Mining can be integrated with backfilling for economic benefits such as maximum ore extraction, improvement of regional stability around the ore body and ensuring the safety of the workforce. The use of backfill has brought many advantages and the choice to select the optimum ore extraction technique with mining methods such as sublevel open stoping, vertical crater retreat and cut-and-fill mining. The post-processed tailings are directed back into the mine stopes as backfill. The concern for the backfilling is increasing and regulations were implemented for mandatory backfilling of some mined stopes (Nantel 1998). The fill quantities per annum are higher, for instance, in Australian open stoping mines, backfilled volumes range from 50,000 cubic metres to two million tonnes or greater per annum (Grice 2003). Hydraulic fills, among many other fill types are widely used with backfilling operations, and popular with low cost, relatively easy preparations. But with pumping at higher water content, for example $70-75 \%$ of solids by weight, a large quantity of excess water is introduced into the stope. Barricades are constructed in place to retain the backfills. However, failure of the barricades associated with hydraulic backfills have been reported (Torlach 2000). Failure of such a slurry retaining barricade not only endangers the miners' lives but also has led to many financial losses such as mining equipment, underground rehabilitation due to flooding and cessation of operations for a considerable time (Duffield et al. 2003; Sivakugan et al. 2006b; Yumlu \& Guresci 2007). A proper understanding of the loadings on the barricades is necessary to design them with confidence, thus ensuring safe and reliable mining practices.

The aspects such as drainage, loading on barricade and filling procedures are to be considered when mine stopes are backfilled with uncemented tailings. There are numerous studies devoted to the aspect of understanding the drainage within backfilled mine stopes (Rankine 2005; Sivakugan et al. 2006a; Helinski 2007) and understanding the stress development within vertical and inclined mine stopes (Pirapakaran 2008; Ting 2011). In situ stress measurements (Grice 1989; Knutsson 1981; Belem et al. 2004; Thompson et 
al. 2009, 2012) and numerical modelling (Aubertin et al. 2003; Li \& Aubertin 2009b; Helinski et al. 2010) can provide an understanding of the arching and stress propagation, thus enabling the development of competent designs about fill procedures and barricades.

Comprehensive tests on properties and behaviour of emplace fills were undertaken by Thomas for Mount Isa Mines (Thomas 1969). Grice (1989) tested real scale bulkheads at Mount Isa Mines and concluded the reasons for the failure as piping. Mitchell (1992), studied the resultant force variation for temporary barricades, locating the barricade at zero setback distance and $100 \mathrm{~mm}$ distance from the stope entrance. Exponential stress reduction was obtained by Mitchell (1992) and later analytically expressed by Li and Aubertin (2009b) and Kuganathan (2002), assuming elastic behaviour with a vertical shear layer element along the drive. Yet when the stope is filled with granular hydraulic fills, the stress values tend to deviate from this analytical expression. However, no study has been undertaken to express the stresses with the setback distance. This paper discusses the stresses on a model barricade measured by earth pressure cells (EPC), while holding the barricade at various distances within the drive and applying the vertical load from the top of the model stope.

Numerical simulations can be used when the scenario is complex and hence the analytical solutions are not readily available. Mine response prediction using numerical codes is an accepted practice in the industry. Numerical simulations on the fill stability of exposed fill masses were reported by Meek and Kirby (1976) followed by Barrett et al. (1978). The first numerical model to simulate the hydraulic filling operation was developed by Isaacs and Carter at 1983 in ISAACS two-dimensional package (Bloss 1992). The stability of fill exposures further investigated by Bloss (1992), then Sivakugan et al. (2005) and Rankine (2005) verified this model for both two dimensions and three dimensions. Though the stress state near the barricade was modelled by Li and Aubertin (2009a) and Fahey et al. (2009) with 2D numerical packages, it is difficult to represent the barricade environment under two-dimensional configuration. Because the model becomes a truly three-dimensional problem, when drive and barricade are added, which would be difficult to simplify into a two-dimensional system. Therefore Fast Lagrangian Analysis of Continua for three dimensions (FLAC3D [Itasca Consulting Group, Inc. 2013]), finite difference simulation software widely used in geomechanics, was used to simulate the stope filling in laboratory.

Every backfilling scenario is specific with stope geometry, mining plan, fill preparation, filling procedures and host rock conditions. However in situ stress measurements related to backfilled stopes are very sparsely available. Therefore deriving a relationship of stress status for a general scenario is undertaken. This study focuses on stress developments through drives towards the barricade in a stope filled with hydraulic fills. The analytical solutions available (e.g. Kuganathan 2002; Li \& Aubertin 2009a) in literature are generally based on a continuum approach, and often underestimate the stresses within the fill. Analytically vertical stress reaches an asymptotic stress and there is no further increase (Marston \& Anderson 1913). Asymptotic stresses are also observed in FLAC3D simulations. In reality, the mine fills are particulate material and the vertical stresses continue to increase with depth, not reaching an asymptotic stress as predicted with continuum approach, while arching carries a fraction of the load (Sivakugan \& Widisinghe 2013). Therefore laboratory testing was undertaken to investigate the stress distributions within stope and drive filled with dry hydraulic fill material under higher stresses. Then the stress propagation through the drive towards the barricade was analysed. Finally stresses calculated from three approaches were compared and implications are discussed.

\section{2}

\section{Methodology}

Practically, it is not possible to have higher stresses in laboratory unless the stope width is larger, as much as $15-20 \mathrm{~m}$, and the depths may be larger than $100 \mathrm{~m}$. A centrifuge was not used in here and a scaled down model was used. If an identical scaled down apparatus is used, the system would have low stresses, around $1 \mathrm{kPa}$, and with the sensitivity of EPC there can be a significant error. Therefore a uniformly distributed load (UDL) is applied through the MTS loading machine at the top of the model the system was subjected to loads of 36, 69, 101, 134, 264, 394, 524, 654, 783 and $913 \mathrm{kPa}$. Then stresses at the stope bottom and at the barricade were recorded at each loading step. Though the stopes are square or rectangular in plan, due 
to the ease of manufacturing and setting the stope, a cylindrical cross-section was used. For square and circular cross-sections with same width, the stress estimated at a height by the Marston's equation would be the same (Fahey et al. 2009; Sivakugan \& Widisinghe 2013). The ratio of stope cross-sectional area to the stope perimeter, dictates the vertical stress variation throughout the stope. Keeping this in mind, the objective was set to find a relationship of the stress at the stope bottom and then the stress at the stope brow and the horizontal stress on the barricade.

A laboratory set up was made with stainless steel, where the frame, which is referred to as the stope herein, was made out of a cylindrical mould of $310 \mathrm{~mm}$ diameter and a height of $465 \mathrm{~mm}$, which is 1.5 times the diameter. A series of square and circular drives were made for diameters of 75, 100, 125 and $150 \mathrm{~mm}$. The barricade was fixed at the end of the drive and the EPC was attached to the centre of the barricade, such that the EPC is flush with the barricade wall. Two other EPCs were placed at the bottom centre and bottom corner of the frame. Then the dry mine fill was poured with a funnel, which is held at the top of the stope, to replicate the fill pouring process. Dry hydraulic fills were used, as it was easier to handle and to understand the mechanism on a simplified approach. Next, the UDL $(q)$ is applied, via the MTS, to the top of the frame, in an incremental steps. The vertical stresses at the bottom of the stope, near the wall, and the horizontal stresses on the drive were recorded onto a data logger. EPCs are calibrated within the laboratory and the calibration coefficient was found out.

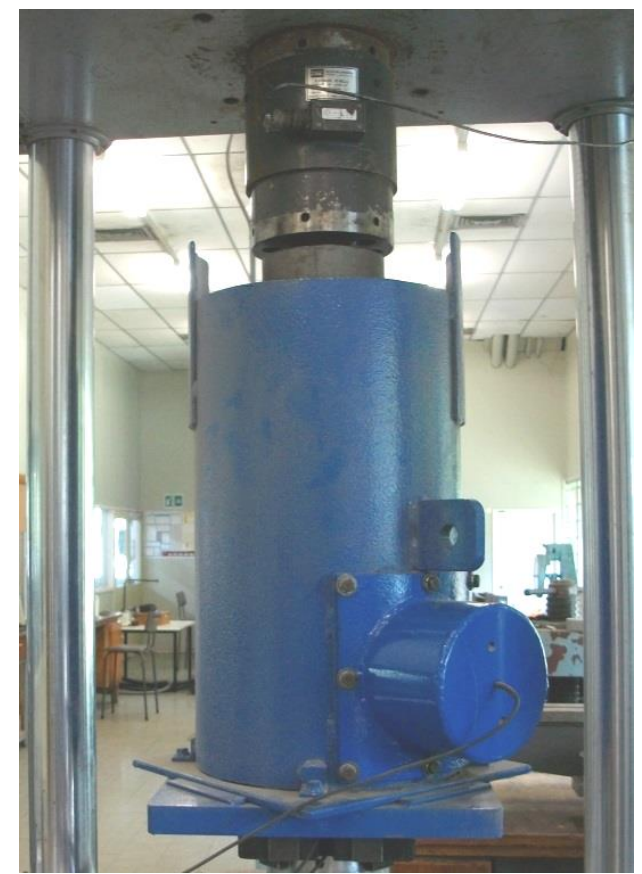

Figure 1 Photograph showing the drive attached model ready to loaded with the MTS machine 


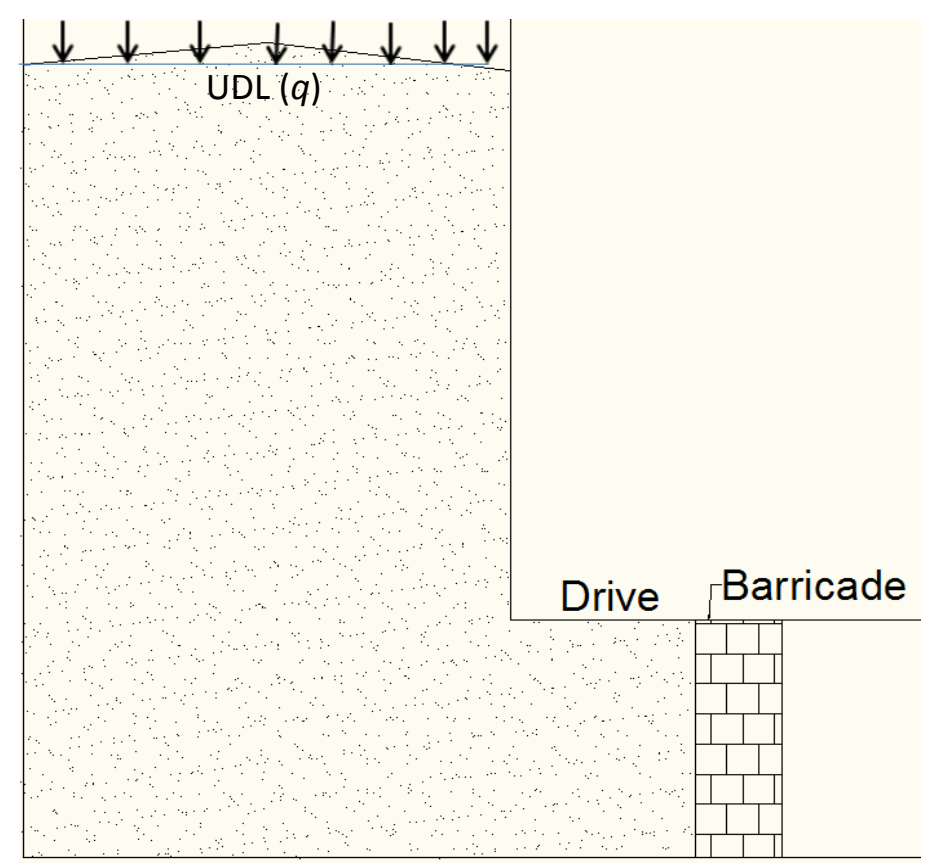

\section{Figure 2 Schematic cross-section of the test setup}

The analytical solutions available in literature (e.g. Kuganathan 2002; Li \& Aubertin 2009a) are based on continuum approach and to calculate the vertical stress at the bottom with applied UDL, the modified Marston's equation (Pirapakaran \& Sivakugan 2007) can be used.

$$
\sigma_{v}=\frac{\gamma D}{4 K \tan \delta}\left[1-\exp \left(-4 K \tan \delta \frac{z}{D}\right)\right]+\mathrm{q} \exp \left(-4 K \tan \delta \frac{z}{D}\right)
$$

Where:

$$
\begin{array}{ll}
\sigma_{v} & =\text { vertical stress at base of the stope entrance. } \\
V & =\text { unit weight of fill. } \\
K & =\text { earth pressure coefficient. } \\
z \quad & =\text { height from top. } \\
D & =\text { width or diameter of the stope. } \\
q \quad & =\text { uniformly distributed load applied at the top. } \\
\delta & =\text { wall friction angle (can be considered as } \varphi \text { for backfilled stopes). }
\end{array}
$$

$$
\sigma_{h}=\left[\frac{h}{H_{d}} \sigma_{h T 0}+\left(1-\frac{h}{H_{d}}\right) \times \sigma_{h B 0}\right] \exp \left[-l \frac{2 \tan \delta}{K_{d l}}\left(\frac{1}{H_{d}}+\frac{K_{d t}}{W_{d}}\right)\right]
$$

Equation (2) was proposed by Li and Aubertin (2009a) to calculate horizontal stress onto the barricade.

Where:
$\sigma_{h} \quad=\quad$ horizontal stress at the barricade.
$h=$ the filled height of the stope.
$\sigma_{h B O}, \sigma_{h T 0}=$ horizontal stress at base and top of the stope entrance, respectively.
$H_{d}=$ total height of the drive.
$K_{d l}=$ earth pressure coefficient in longitudinal direction within the drive.
$K_{d t}=$ earth pressure coefficient in transverse direction within the drive. 


$$
\begin{array}{lll}
W_{d} & = & \text { width of the drive. } \\
I & = & \text { setback distance. }
\end{array}
$$

However, Kuganathan (2002) proposed a simplified equation to calculate the stress on barricade:

$$
\sigma_{b}=\sigma_{o} \times \exp \left[-\frac{P K_{0} \tan \varphi}{A} L\right]
$$

Where:

$\sigma_{0}, \sigma_{b}=$ horizontal stress at stope entrance and at the barricade, respectively.

$P \quad=$ perimeter of the drive.

$A=$ cross-sectional area of the barricade.

$L \quad=$ setback distance.

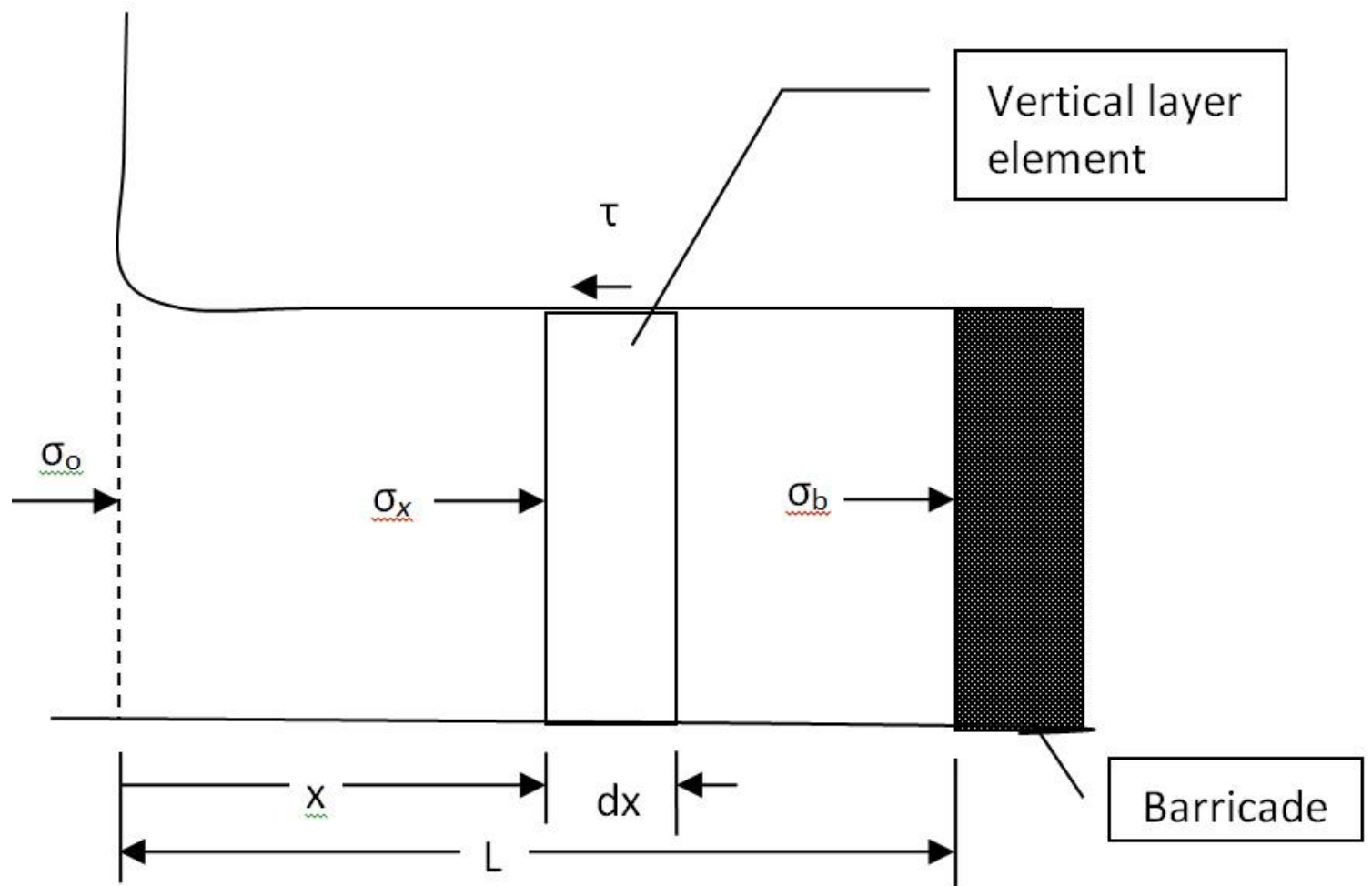

Figure 3 Schematic diagram showing the stope, drive and vertical layer element for stress calculations

The stope, drive and barricade were simulated with equidimensional block elements of dimensions of $5 \mathrm{~mm}$. Constitutive model parameters and properties for hydraulic fills and barricade are given in Table 1. Here the barricade is assumed to be built from porous bricks and the interface between the stope and fill (where the walls are rough) and interface between barricade and mine fill as well as drive and mine fill also included. This was also simulated numerically using FLAC3D and the stresses onto the barricade were recorded. 
Table 1 Geomechanical properties used with FLAC3D model for mine fill, barricade bricks, rock surrounding and interface

\begin{tabular}{lll}
\hline Material & Property/modelling parameter & \\
\hline Barricade bricks & Young's modulus & $* 1.99 \mathrm{GPa}$ \\
& Poisson's ratio & $* 0.2$ \\
& Density & $* 1,927 \mathrm{kgm}^{-3}$ \\
Rock surrounding & Young's modulus & $* 20 \mathrm{GPa}$ \\
& Poisson's ratio & $* 0.3$ \\
& Density & $* 2,700 \mathrm{kgm}^{-3}$ \\
Mine fill & Young's modulus & $* 50 \mathrm{MPa}$ \\
& Poisson's ratio & $* 0.25$ \\
& Density & $1,800 \mathrm{kgm}^{-3}$ \\
& Internal friction angle & $41^{\circ}$ \\
Interface & Interfacial friction angle & $40^{\circ}$ \\
& Normal and shear stiffness & $* 2,689 \mathrm{GPa}$ \\
& Dilation angle & $0^{\circ}$ \\
\hline
\end{tabular}

*These properties were chosen based on literature and the FLAC3D (Itasca Consulting Group, Inc. 2012) manual.

\section{Results and discussion}

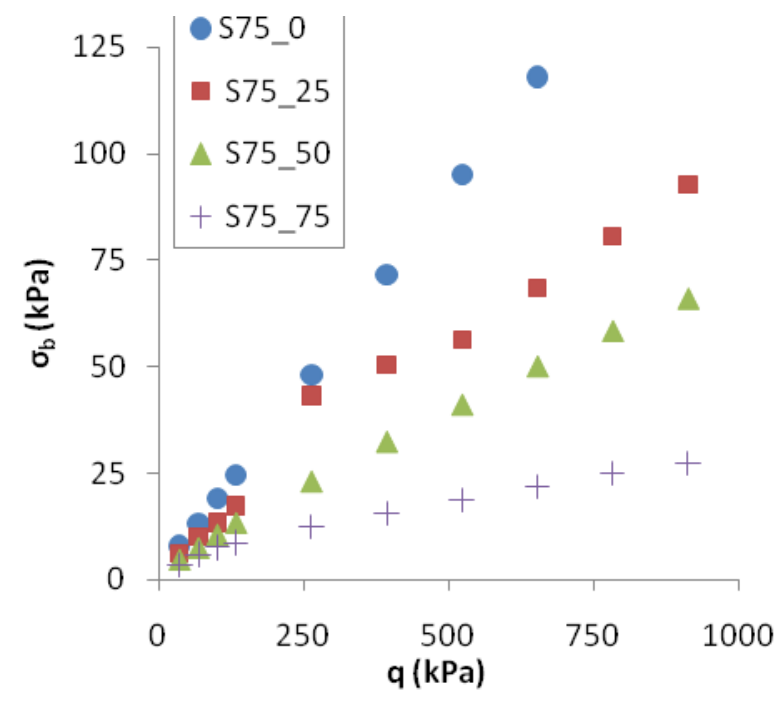

(a)

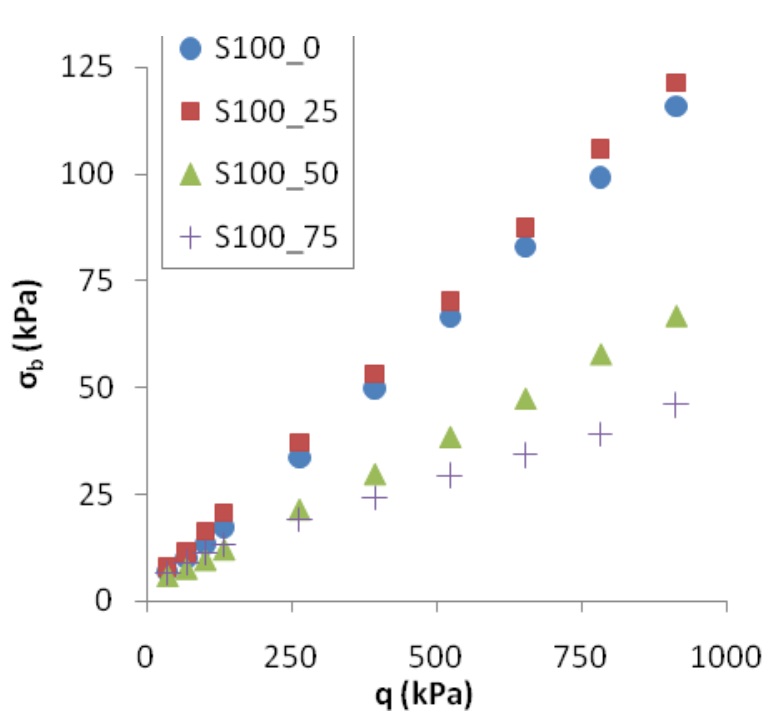

(b)

Figure 4 Variation of horizontal stress on the barricade with the change of setback distance to $0,25,50,75 \mathrm{~mm}$ in square drives; (a) width $75 \mathrm{~mm}$; (b) width $100 \mathrm{~mm}$

Figure 4 summarises the laboratory test results for square shaped drives of widths 75 and $100 \mathrm{~mm}$. In both cases when the barricade is at zero setback distance, flushed with the stope, the barricade stress is highest. When the setback distance is maximum $(75 \mathrm{~mm})$, the stress felt is minimum. As the setback distance is increased, more surface area along the drive contribute to arching and hence the stress on the barricade is greatly reduced (Figure 4(a)). However, when the drive dimension is $100 \mathrm{~mm}$ and setback distance is $25 \mathrm{~mm}$, the stress on the barricade tends to larger than for setback distance of $25 \mathrm{~mm}$ (Figure 4(b)). This is 
because the particle rearrangement in the stope after filling and handling. Measures were taken to make the rearrangement as possible, such as keeping the funnel at the same height, using the same mechanism to bring the filled stope to MTS machine. However it is observed that the loading plate displacement was not uniform for all the cases, implying a difference of particle packing within the stope.

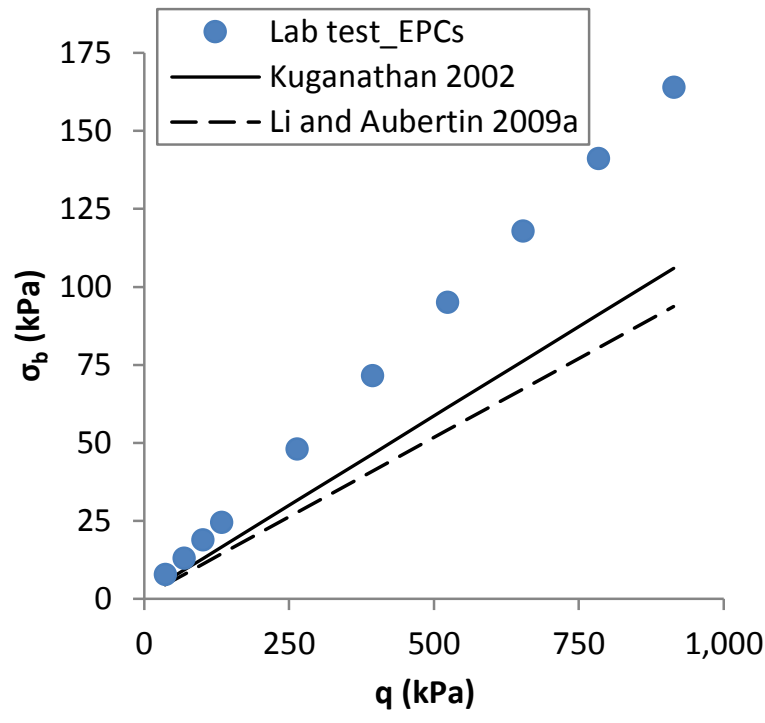

(a)

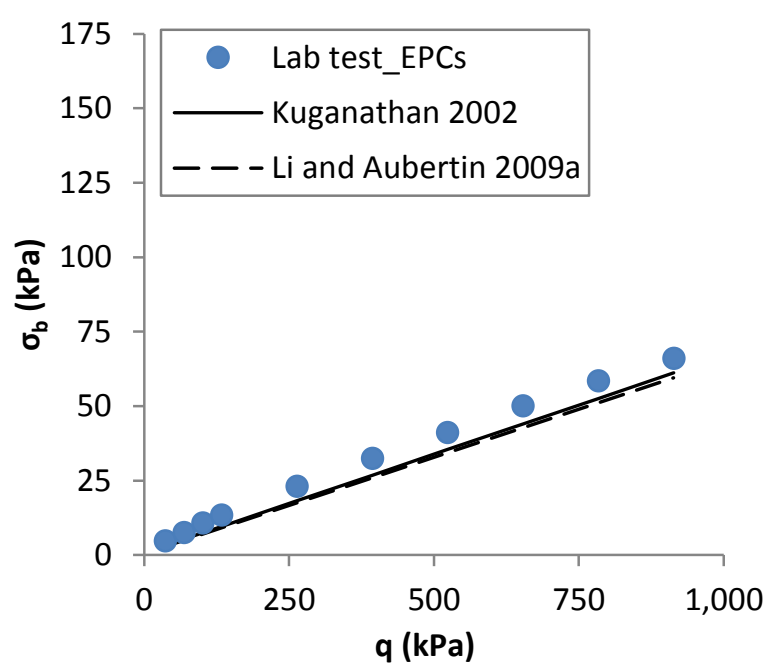

(c)

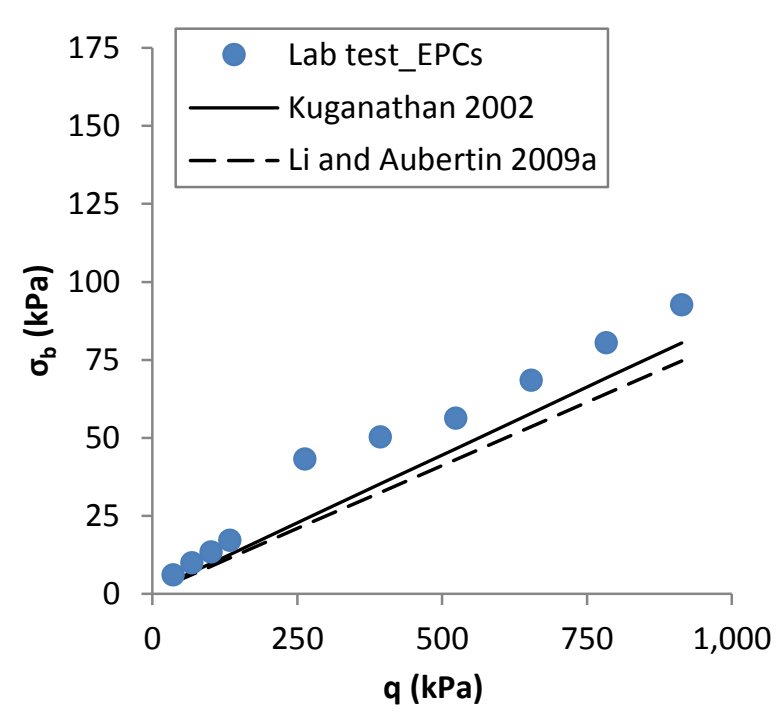

(b)

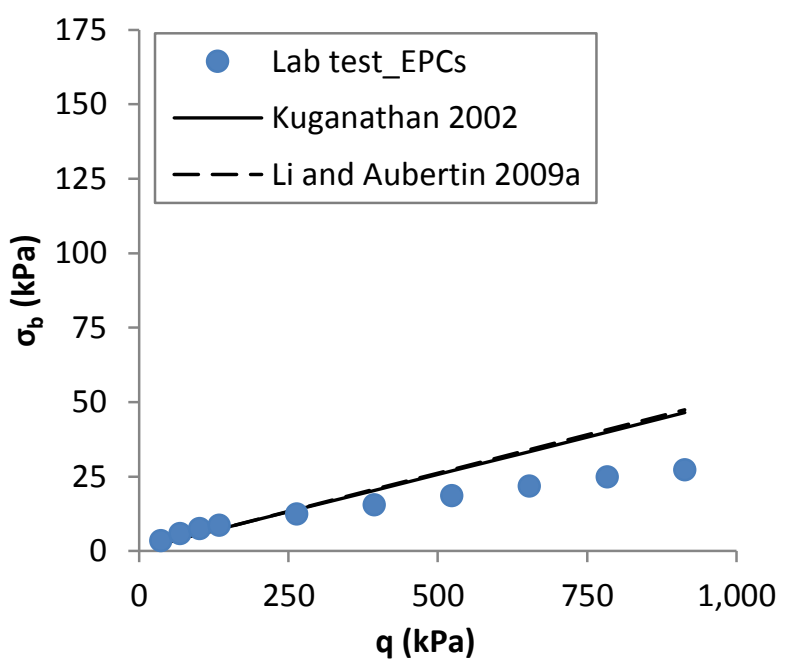

(d)

Figure 5 Horizontal stress on the barricade ( $\sigma b)$, with respect to the UDL (q) and the results are compared with analytical equations within square drives of width $75 \mathrm{~mm}$ at various setback distances of; (a) $0 \mathrm{~mm}$;

(b) $25 \mathrm{~mm}$; (c) $50 \mathrm{~mm}$; (d) $75 \mathrm{~mm}$

In Figure 5 the laboratory test results are compared with available analytical solutions. All the laboratory tests were repeated three times and the average is included under the 'Lab test_EPCs' title in legand. A maximum variation of $10 \%$ was observed within the same test. As it expected, with the increased $q$, the stress felt at the barricade is increased. Additionally when the setback distance is increased, the stress at the barricade is decreased. Approximately, with the increase of setback distance of $25 \mathrm{~mm}$, reduced the stress at the barricade about $40 \%$ (Figure 5(a) versus (b) or (c) versus (d)). Interestingly, when the setback distance is $0 \mathrm{~mm}$, the analytical equation overestimates the vertical stress and with the increase of setback 
distance the error of estimation is less. Finally at a setback distance of $75 \mathrm{~mm}$, analytical equation underestimates the barricade stress. Neither the equation by Kuganathan (2002) nor Li and Aubertin (2009a) cannot describe the stress variation completely. Most of the time, both analytical equation variations are matching, but Kuganathan's (2002) equation has a low error of estimation than the other.

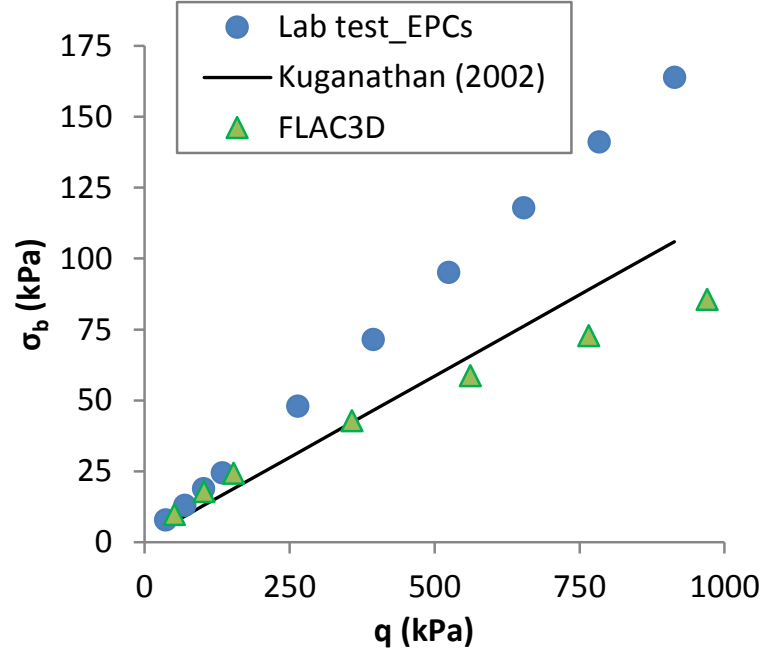

(a)

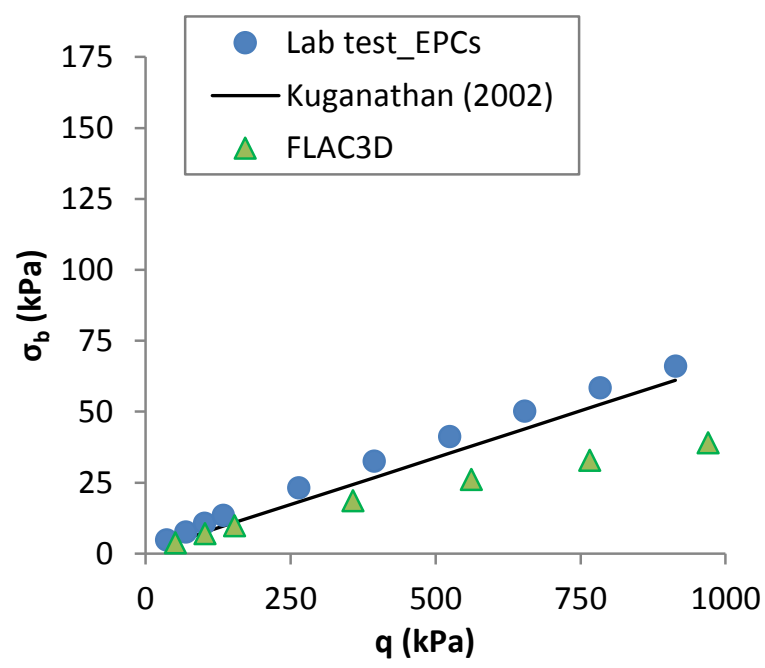

(c)

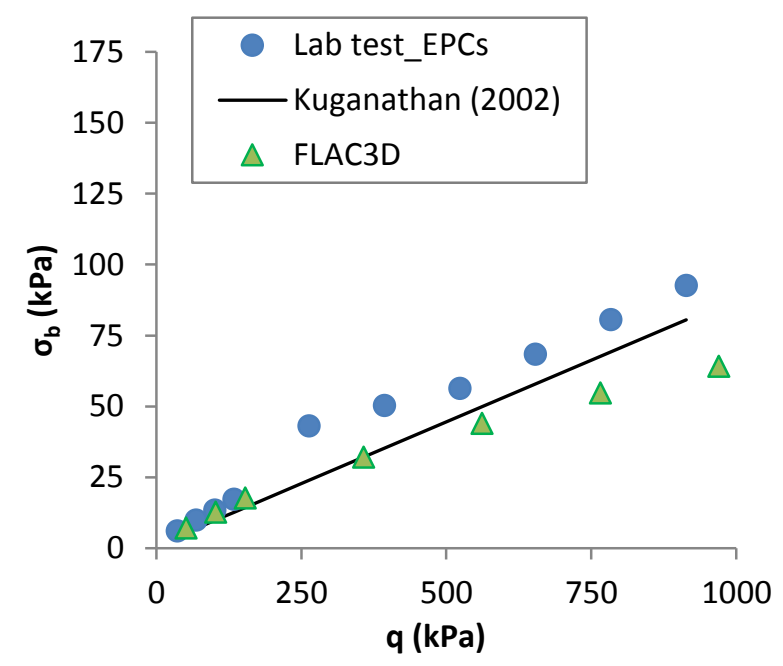

(b)

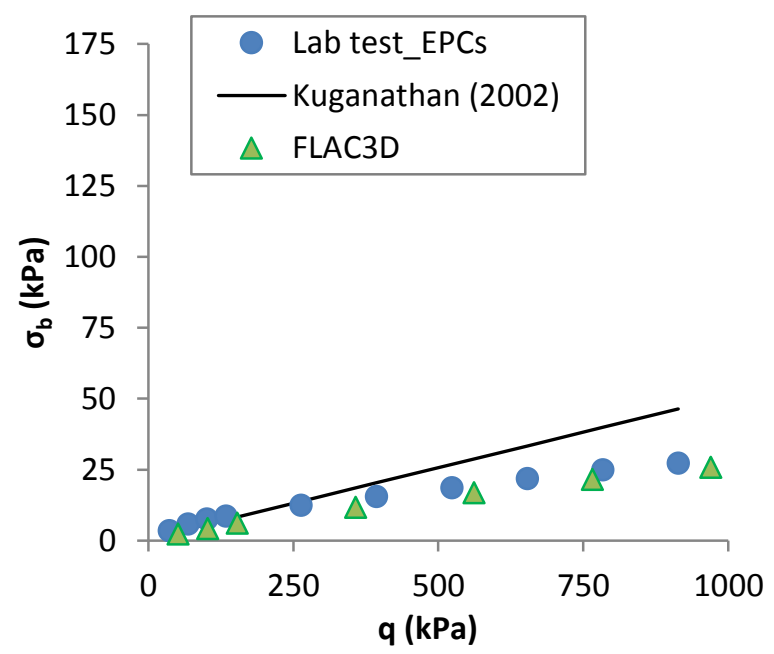

(d)

Figure 6 Stress on barricade variation for square drives of width $75 \mathrm{~mm}$, compared with lab tests, analytical equation and $\mathrm{FLAC}_{3} \mathrm{D}$ results; (a) setback distance o $\mathrm{mm}$; (b) setback distance $25 \mathrm{~mm}$; (c) setback distance $50 \mathrm{~mm}$; (d) setback distance $75 \mathrm{~mm}$

Comparison of three approaches is shown in Figure 6, where the FLAC3D results are also included among analytical and lab test results. Here the FLAC3D simulations underestimate the stresses on the barricade for all the setback distances. FLAC3D assumes the material as a continuum and though a higher surcharge is applied at the top, the stress transfer via the continuum is less. As an example, a surcharge of $913 \mathrm{kPa}$ results in $85 \mathrm{kPa}$ stress on the barricade when the setback distance is zero (Figure 6a).

Most of the cases, the analytical and numerical approaches underestimate the loads on the barricade within the backfilled stope. This is because in continuum background, though a large surcharge is applied at the top, the stress variation reaches the asymptotic stress. As in Equation 1, the vertical stresses asymptote is $[\gamma B / 4 K \tan \delta]$ and this asymptotic stress does not depend on the surcharge applied. This phenomenon is further illustrated in Figure 7, where a stress variation is shown for a drive of $75 \mathrm{~mm}$ and setback distance 
of $25 \mathrm{~mm}$. Though a high surcharge $(913 \mathrm{kPa})$ is applied at the top, the stress contours does not vary along the drive, which implies the stress transfer within the drive is minimum and therefore the stress recorded at the barricade is less.

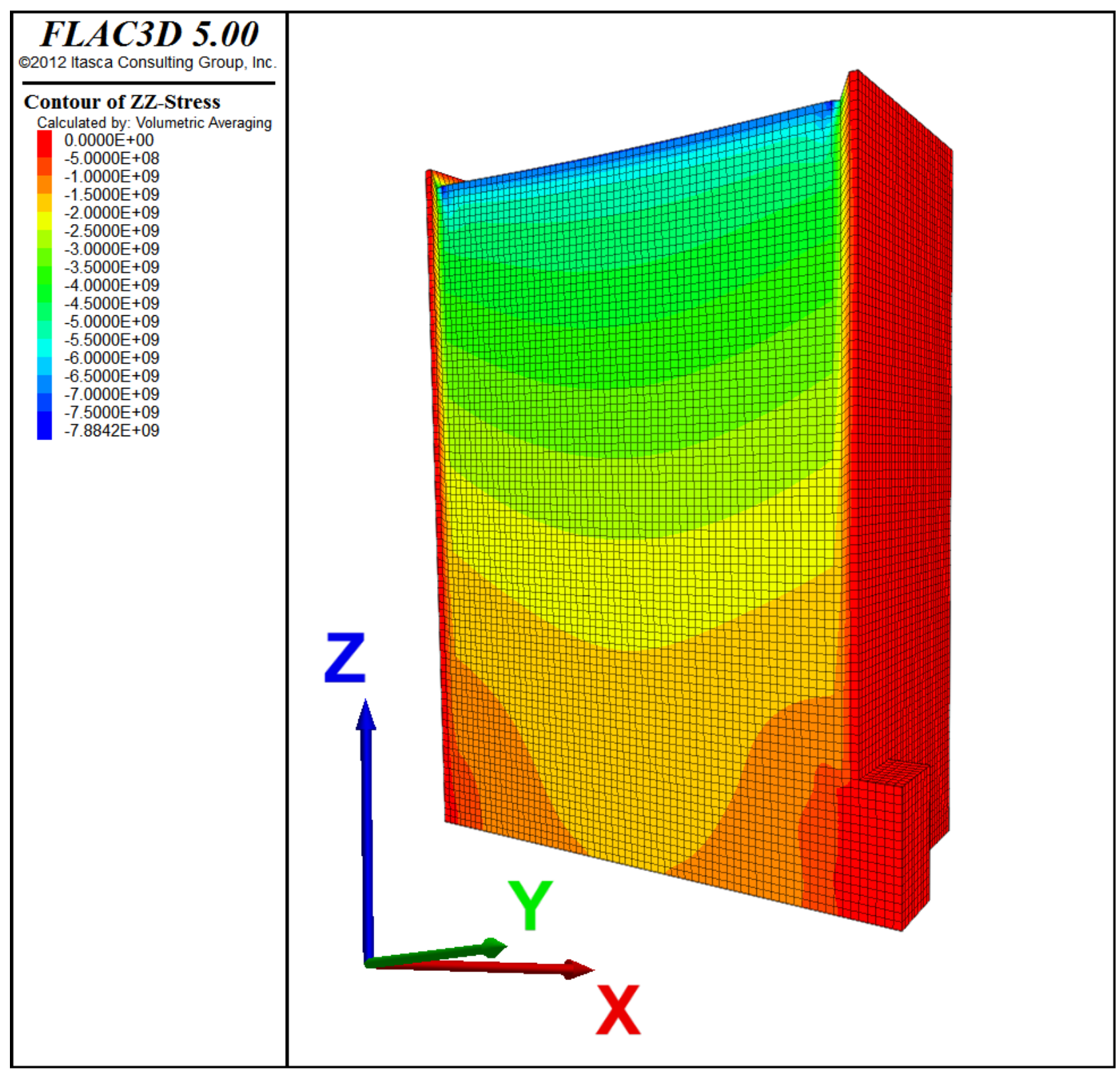

Figure 7 Stress contours plot after the $\mathrm{FLAC}_{3} \mathrm{D}$ simulations; for the setup with a $75 \mathrm{~mm}$ drive and a setback distance of $25 \mathrm{~mm}$

A complete continuum approach might not be the suitable estimation method and it is appropriate to use an integrated simulation technique to capture the behaviour of mine fill. There is a possibility to use the built-in continuum-particulate hybrid modelling facilities (FLAC-PFC by Itasca), and then compare the results with laboratory tests. The current study will be advanced into FLAC-PFC hybrid models and it is expected to capture the stress developments related to mine fill with a less error margin. However, due to the level of uncertainty of model predictions and level of simplification, simulations are often questioned (Bloss 1992). Therefore further tests on mine fill in laboratory or in situ stress measurements will yield great understanding on this aspect. 


\section{$4 \quad$ Conclusions}

Estimation of loads or stresses on barricades is important for reliable stress estimations for barricade design and fill monitoring activities. Three approaches, such as laboratory tests, analytical equations and numerical simulations were considered in this study. In summary (Figures 4, 5 and 6), numerical technique underestimates stresses on to the barricade. Most of the time analytical equation underestimates the stress too. However, at a setback distance of $75 \mathrm{~mm}$, analytical equation overestimates the stress.

Both estimation schemes, analytical equations as well as FLAC3D, assume the material to behave as a continuum and derives results accordingly. Out of all, laboratory tests have shown that the system cannot be assumed as a continuum and it is required to emphasise the modelling with discrete elements or hybrid models.

\section{References}

Aubertin, M, Li, L, Arnoldi, S, Belem, T, Bussière, B, Benzaazoua, M \& Simon, R 2003, 'Interaction between backfill and rock mass in narrow stopes', in PJ Culligan \& AJ Whittle (eds), Proceedings of the 12th Pan American Conference on Soil Mechanics and Geotechnical Engineering, Verlag Glückauf GmbH, Essen, pp. 1157-64.

Barrett, JR, Coulthard, MA \& Dight, PM 1978, 'Determination of fill stability', Proceedings of the 12th Canadian Rock Mechanics Symposium, Canadian Institute of Mining, Metallurgy and Petroleum, Westmount, pp. 85-91.

Belem, T, Harvey, A, Simon, R \& Aubertin, M 2004, 'Measurement and prediction of internal stresses in an underground opening during its filling with cemented fill', in E Villaescusa \& Y Potvin (eds), Proceedings of the Fifth International Symposium on Ground Support in Mining and Underground Construction, Balkema, Rotterdam, pp. 28-30.

Bloss, M 1992, 'Prediction of cemented rock fill stability-design procedures and modelling techniques', PhD thesis, University of Queensland.

Duffield, C, Gad, E \& Bamford, W 2003, 'Investigation into the Structural Behaviour of Mine Brick Barricades', Aus/MM Bulletin, vol. 2, pp. 44-50.

Fahey, M, Helinski, M \& Fourie, AB 2009, 'Some aspects of the mechanics of arching in backfilled stopes', Canadian Geotechnical Journal, vol. 46, pp. 1322-36.

Grice, AG 1989, 'Fill research at Mount Isa mines limited', in FP, Hassani, MJ, Scoble \& TR Yu (eds), Proceedings of the Fourth International Symposium on Mining with Backfill, Balkema, Rotterdam, pp. 15-22.

Grice, AG 2003, Mining with Backfill, viewed 4 Sep 2011, AMC's newsletter "Digging Deeper" on current events and modern mining methodology.

Helinski, M 2007, 'Mechanics of mine backfill', PhD thesis, The University of Western Australia.

Helinski, M, Fahey, M \& Fourie, AB 2010, 'Coupled two-dimensional finite element modelling of mine backfilling with cemented tailings', Canadian Geotechnical Journal, vol. 47, pp. 1187-200.

Itasca Consulting Group, Inc. 2012, FLAC3D 5.0 - Fast Lagrangian Analysis of Continua, Version 5.0 User's Guide, Itasca Consulting Group, Inc., Minneapolis, Minnesota.

Itasca Consulting Group, Inc. 2013, FLAC3D 5.0 - Fast Lagrangian Analysis of Continua, Version 5.0, Itasca Consulting Group, Inc., Minneapolis, Minnesota, http://www.itascacg.com/software/flac3d.

Knutsson, S 1981, 'Stresses in the hydraulic backfill from analytical calculations and in-situ measurements', in O Stephansson \& MJ Jones (eds), Proceedings of the Conference on the Application of Rock Mechanics to Cut and Fill Mining, The Institution of Mining and Metallurgy, London, pp. 261-8.

Kuganathan, K 2002, 'A method to design efficient mine backfill drainage systems to improve safety and stability of backfill bulkheads and fills', Proceedings of the 8th AusIMM Underground Operators' Conference "growing our underground operations", Australasian Institute of Mining and Metallurgy, Carlton, pp. 181-8.

Li, L \& Aubertin, M 2009a, 'Horizontal pressure on barricades for backfilled stopes. Part I: Fully drained conditions', Canadian Geotechnical Journal, vol. 46, no. 1, pp. 37-46.

$\mathrm{Li}, \mathrm{L} \&$ Aubertin, M 2009b, 'Numerical investigation of the stress state in Inclined backfilled stopes', International Journal of Geomechanics, vol. 9, pp. 52-62.

Marston, A \& Anderson, AO 1913, 'The theory of loads on pipes in ditches, and tests of cement and clay drain tile and sewer pipe', lowa State University Engineering Experiment Station, Bulletin number 31.

Meek, JL \& Kirkby, RW 1976, 'Finite element analysis of cemented fill exposures', in CS Desai (ed.), Proceedings of the 2nd International Conference on Numerical Methods in Geomechanics, American Society of Civil Engineers, Reston.

Mitchell, R 1992, Centrifuge model studies of fill pressures on temporary bulkheads, CIM Bulletin, vol. 85, no. 960, pp. 48-54.

Nantel, J 1998, 'Recent developments and trends in backfill practices in Canada', in M Bloss (ed.), Proceedings of the Sixth International Symposium on Mining with Backfill, Australasian Institute of Mining and Metallurgy, Carlton, pp. 11-14.

Pirapakaran, K 2008, 'Load-deformation characteristics of minefills with particular reference to arching and stress developments', $\mathrm{PhD}$ thesis, James Cook University.

Pirapakaran, K \& Sivakugan, N 2007, 'Arching within hydraulic fill stopes', Geotechnical and Geological Engineering, vol. 25, no. 1, pp. 25-35. 
Rankine, KJ 2005, 'An investigation into the drainage characteristics and behaviour of hydraulically placed mine backfill and permeable minefill barricades', PhD thesis, James Cook University.

Sivakugan, N, Rankine, KJ \& Rankine, RM 2005, 'Geotechnical aspects of hydraulic filling of underground mine stopes in Australia', in B Indraratna \& J Chu (eds), Elsevier Geo-Engineering Book Series Volume 3, Ground Improvement: Case Histories ElsevierLtd., Kidlington, Oxford.

Sivakugan, N, Rankine, KJ \& Rankine, RM 2006a, 'Permeability of Hydraulic Fills and Barricade Bricks', Geotechnical and Geological Engineering, vol. 24, no. 3, pp. 661-73.

Sivakugan, N, Rankine, RM, Rankine, KJ \& Rankine, KS 2006b, 'Geotechnical considerations in mine backfilling in Australia', Journal of Cleaner Production, vol. 14, pp. 1168-75.

Sivakugan, N \& Widisinghe, S 2013, 'Stresses Within Granular Materials Contained Between Vertical Walls', Indian Geotechnical Journal, vol. 43, no. 1, pp. 30-8.

Thomas, EG 1969, 'Characteristics and behaviour of hydraulic fill material', PhD thesis, University of Queensland.

Thompson, BD, Grabinsky, MW, Bawden, WF \& Counter, DB 2009, 'In-situ measurements of cemented paste backfill in long-hole stopes', in M Diederichs \& Grasselli G (eds), Proceedings of the 3rd CANUS Rock Mechanics Symposium, University of Toronto Press, Toronto, paper no. 4061.

Thompson, BD, Bawden, WF \& Grabinsky, MW 2012, 'In-situ measurements of cemented paste backfill at the Cayeli Mine', Canadian Geotechnical Journal, vol. 49, no. 7, pp. 755-72.

Ting, CH 2011, 'Arching in granular materials with particular reference to inclined mine stopes', PhD thesis, James Cook University. Torlach, J 2000, 'Potential hazards associated with mine fill', Safety Bulletin No: 55, 29 June 2000.

Yumlu, M \& Guresci, M 2007, 'Paste backfill bulkhead failures and pressure monitoring at Cayeli mine', CIM Bulletin Technical Papers. 
